\title{
Self-Micro-Emulsifying Drug Delivery System to Enhance the Solubility of the Hydrophobic Drugs
}

\author{
Gautam Priyanka and Shastri Divyesh* \\ Department of Pharmaceutics, KB Institute of Pharmaceutical Education \& Research, India
}

Submission:December 20, 2017; Published:April 10, 2018

*Corresponding author: Shastri Divyesh, K.B. Institute of Pharmaceutical Education \& Research, a Constituent College of Kadi Sarva Vishwavidyalaya, Gh-6 Road, Sector-23, Kadi Campus, Gandhinagar, Gujarat, India, Email: priyankagautam036@gmail.com/divyeshshastri@gmail.com

Abstract

Self-micro-emulsifying drug delivery system is the one of the approach for enhancing the solubility of the hydrophobic drug. The drugs which are insoluble in water can be formulated in this method by solubilising it in the lipid vehicle to absorb through the membranes. The lipid and surfactants are used to increase the solubility of the drug and improve absorption. This improves the dissolution rate of the drug by increasing its solubility. Many of the hurdles and solutions are described in this article. This technique gained attention as it also enhances the bioavailability of the drug. This article has complete review about SMEDDS for present work and for future perspective also.

Keywords: Hydrophobic; Lipid; Surfactants; Dissolution; Bioavailability

\section{Introduction}

Oral route is the most preferred, affordable and convenient route to administer a drug. The pathways through which the drug distributed can be through gastro-intestinal tract or lymphatic system. They are preferable as they are easy to administrate, low cost, and low patient compliance. Oral route mainly focuses on some of the main absorption sites of the body which is mouth, stomach, intestine, rectum etc. some of the dosage forms are solid oral dosage forms like tablets, capsule, pellets etc. and on the other hand liquid oral dosage forms like emulsion, suspension, gels etc. As of the poor patient compliance and difficult to administer the drug to paediatric and geriatric patients, fast dissolving techniques are introduced to administer the drug for immediate action and for better patient compliance. The dosage form includes the tablets and films. The dosage forms that are available are oral disintegrating tablet, mouth dissolving tablet, mouth melting tablet, oral disintegrating film, and mouth melting wafer, mouth dissolving film and sublingual tablet or film.

The fast dissolving technology is one of the oral route dosage form technique eases the transport of drugs to act immediately. They permeate through interstitial spaces by the mucosa and directly go into the systemic circulation for the immediate action. They disintegrate rapidly and dissolve in saliva and absorb through the mucosal surface.

Advantages of fast dissolving dosage forms:

1. Self-medication
2. No first pass metabolism
3. No use of water
4. Improved patient compliance
5. Ease of manufacturing
6. Lack of pain
7. Immediate action
8. Easy for pediatric and geriatric patients
9. Ease of administration (mentally ill, disabled, uncooperative)

10. Leaves no residue on mouth after administration

\section{Faster absorption \\ 12. Cost effectiveness}

The drugs which are hydrophilic (soluble in aqueous solvents) are considered for the fast dissolving techniques but for those which are lipophilic cannot be formulated as they are insoluble in aqueous solvent and soluble in non-aqueous solvents. The lipid formulations can enhance the solubility of the hydrophobic drug are liposomes, solid lipid nano-particles, selfdispersing tablets, solid dispersions etc. the drug formulated should be permeable across the gastric mucosa and should be least sparingly soluble in water (BCS class II and IV). 


\section{SMEDDS}

The solubility of hydrophobic drugs can be enhanced by various methods and one of them are self-micro-emulsifying drug delivery system(SMEDDS) or self-emulsifying drug delivery system (SEDDS) as they also enhance the permeability and bioavailability of the hydrophobic drugs without going into first pass metabolism [1,2]. Self-micro-emulsifying drug delivery systems (SMEDDS) are the isotropic mixture and lipid based formulations given by oral route. The hydrophobic drug which is soluble in the oil can be formulated in this technique. The mixture consists of oil which has to be in the range of less than $100 \mathrm{~nm}$ droplet size. The bioavailability of the hydrophobic drug will be enhanced by in situ solubilisation of the drug absorbed by the lymphatic pathway. The SMEDDS will get in contact with the GIT lumen and forms w/o micro emulsion with the GI fluid. This method is advantageous for the poorly water-soluble drugs with the lipid as vehicle and surfactants to form w/o micro emulsion within the GIT lumen. For example-Fexofenadine [3], domeperidone [4], danazol [5] etc.,

The first purpose to use the lipid is to solubilise the drug and the second one is to stimulate the biliary and pancreatic secretion which helps for the digestion of the lipids. The enzyme presents in the secretions act at the lipid/water interface and forms the mixed micelle which helps in the drug solubilisation [6]. Highly lipophilic drug $(\log \mathrm{P}>5$ ) show high solubility in the triglycerides $(>50 \mathrm{mg} / \mathrm{L}$ ) which is good for lymphatic pathways. In the cellular level, the lipids open the tight junctions in the intestine which increases the permeability only for the class IV drugs (low solubility and low permeability) [7-9].

\section{Advantages}

1) Increase bioavailability by decrease in dose.

2) Decrease in food effects.

3) Prolong release of medicament.

4) For both liquid and solid dosage forms.

5) Overcome of the irritation caused by the contact between drug and the wall of GIT.

6) Simple mixing.

7)Low energy consumption.

8)Easy manufacturing process.

9) Less time required.

10)Hydrophobic drugs can be absorbed by stable plasmatime profile.

11)Drugs which can be degraded by GIT can be used.

\section{Composition}

1. Lipids $[10,11]$

2. Surfactants
3. Co-surfactants [12]

4. Hydrophobic drug [13]

\section{Lipids}

It solubilizes the drug and access to the lymphatic circulation for the absorption. They are used in the concentration of less than $20 \% \mathrm{w} / \mathrm{w}$ of the formulation. The lipids that are available are digestive lipids such as triglyceride, diglyceride, fatty acids, phospholipids and cholesterol improves the bioavailability of the drug [14]. The non-digestive ones are not used as they decrease the bio-availability and give impairment of the absorption. Edible oils are not useful as they give no solubilization of the drug and require large molecular volume. For self-micro-emulsifying drug delivery system, triglyceride with long and medium chain length (LCT and MCT) [15].

The medium chain triglyceride (MCT) [16]: -

1) Digestible

2) Greater fluidity

3) Increase solubility

4) Good emulsifying property

5) Minimizes oxidation

6) Increase drug absorption

7) Positive effect on bioavailability

8) No access to lymphatic system

For example - re-esterification of fractionated coconut oil fatty acid with glycerin, palm seed oil, etc.

Long chain triglyceride (LCT)

1) Vegetable source

2) Enhance the lymphatic pathways

3) Safe for the use

4) Increase bioavailability

For example-cottonseed oil, soya bean oil, safflower oil, olive oil, peanut oil, sesame oil, wheat germ oil, rice bran oil, corn oil and castor oil.

\section{Surfactants}

They are amphiphilic in nature and HLB more than 12 are considered for the method which are water soluble. The concentration range taken should be between $30-60 \% \mathrm{w} / \mathrm{w}$ of the formulation.

1) Give self-emulsification property

2) Solubilizes the hydrophobic drug

3) Dissolution rate can be improved

4) In vivo Inhibitory effect on drug precipitation 
5) Improves permeability by opening the tight junctions

6) Stabilizes the micro emulsion system

Selection of surfactant are based on HLB value, if the HLB value are high then it facilitates $\mathrm{o} / \mathrm{w}$ microemulsion and if HLB $>12$ increases the solvent capacity of the formulations in which the droplet size will be $<100 \mathrm{~nm}$.

Natural surfactant such as lecithin are less toxic but have limited self-emulsification efficiency. Anionic surfactants such as potassium laurate and sodium lauryl sulphate are used and in cationic surfactant, quaternary ammonium is used.

The best matches for the formulation are non ionic surfactants which are,

1) High HLB value

2) Less toxic than ionic

3) Greater emulsion stability

For example, oleates, polysorbates (tween 40, 60 and 80), polyoxyls which has HLB value 2 to $18[17,18]$. Disadvantages include GI irritation, low emulsification efficiency, dehydration effect on SGC and HGC. The combination of non-ionic and ionic surfactants gives increase in microemulsion, but it gives possible synergism.

\section{Co-solvents and co-surfactants}

They should be hydrophilic in nature.

Purpose

1) Access the entry of water into the formulation

2) Assist the dispersion process

3) Imparts the flexibility to the interface

The range of co-solvents and co-surfactants should be in 20$50 \% \mathrm{w} / \mathrm{w}$ of the formulation and always $30 \% \mathrm{w} / \mathrm{w}$ more than the concentration of the surfactants. The HLB value of the sosurfactants should be 10-14. Alcoholic surfactants are not used in the formulation as they cause precipitation of the drug. Short chain alcohols are the best to formulate in SMEDDS which are ethanol, polypropylene glycol, polyethylene glycol.

\section{Drug candidate}

1) Solubility: The drug should be insoluble in water. The $\log \mathrm{P}$ should be greater than 4 (lipophilic), high solubility in LCT for lymphatic absorption ( $>50 \mathrm{mg} / \mathrm{ml}$ ).

BCS class II and IV [19]

2) Low dose [20]: To increase the bioavailability of the drug and to decrease particle size, the dose should be low mainly $<40 \mathrm{mg}$.

3) Poor BA: The bioavailability should be low as to enhance the solubility of the drug [20-23].
4) Low melting point: The m.p should be low for the better absorbability of the drug [24].

5) Should be chemically and physically stable in SMEDDS

\section{Formulation}

\section{Screening of excipients}

1) Solubility studies:

Method: Shake flask method in which the drug is solubilized with the excipients (excess amount) 0.5gm each of the solvent. It is shaken for the $48 \mathrm{hrs}$ a water bath shaker at room temperature. The solution is then centrifuged for 15 minutes. Then the supernant is filtered $(0.45 \mathrm{um})$. Then the drug content will be determined by HPLC [25-31]

2) Screening of surfactants and co-surfactants for their self-emulsification ability: Equal proportions of oil and surfactants (0.3gm) are homogenized for $2 \mathrm{~min}$ and then warmed for 30 secs $\left(40-45^{\circ} \mathrm{C}\right)$. Then the $50 \mathrm{mg}$ of prepared isotropic mixture is added to distilled water and allowed to stand for $2 \mathrm{hrs}$. The prepared micro emulsion are filtered and tested for clarity, turbidity and \% transmittance (wavelength-638nm). If the resultant \% transmittance is high then the emulsification efficiency will be high, low flask inversions, clear emulsion if formed then those surfactants and co-surfactants are selected.

\section{Construction of pseudoternary phase diagram}

Co surfactant + surfactant $=$ Smix

It helps in deciding the ratio of oil, surfactant and cosurfactant to be formulated in the SMEDDS by pseudo ternary diagram. The ratio of oil, surfactant and co surfactant are to be added in vials with $5 \% \mathrm{w} / \mathrm{w}$ of water. They are centrifuged for $2-3 \mathrm{~min}$ for phase separation. They are incubated for $48 \mathrm{hrs}$ $\left(25^{\circ} \mathrm{C}\right)$. The vials are shaken and the ratio of formulation which shows clear and isotropic mixture are selected $[32,33]$.

\section{Preparation}

The selected hydrophobic drug, oil, surfactant, and cosurfactant are vortexed for $5-10 \mathrm{~min}$ in a magnetic stirrer. The prepared emulsion is to be placed in oven at $50^{\circ} \mathrm{C}$ for $1 \mathrm{hr}$. Then it is checked for turbidity. If required vortex for 48 hours until clear solution obtained or heat it [34-37].

\section{Characterization}

a) Visual evaluation: The prepared SMEDDS are dissolved in water, if the emulsion appears opaque or milky white then it is macro emulsion and if it appears clear, isotopic and transparent then it is micro emulsion [38].

b) Droplet size analysis: SMEDDS are dissolved in water and tested for scanning electron microscope (SEM) which ranges 10 to $5000 \mathrm{~nm}$. The size should be narrow and less than $100 \mathrm{~nm}$. 
c) Zeta Potential Measurement: The SMEDDS are diluted and checked for stability under Zeta potential analyzer. Higher the zeta potential there will be good stability. If the zeta potential is negative, then there is presence of fatty acid if they are positive then there is presence of cationic lipids $[39,40]$.

d) In-vitro dissolution time OR dispersibility test: Apparatus: USP type II paddle are used with 50rpm speed at $37^{\circ} \mathrm{C}$. The medium used $200 \mathrm{ml}$ of $0.1 \mathrm{~N}$ HCL.

e) Cloud point determination: The prepared formulation $(0.5 \mathrm{ml})$ are added to the distilled water $(50 \mathrm{ml})$ are to be placed on water bath. The temperature is to be raised at the rate of $0.5{ }^{\circ} \mathrm{C} / \mathrm{min}$ then the emulsion is cooled till they become cloudy and they are checked spectrophotometrically.

f) Viscosity measurement: Rheometers-Brookfield cone and plate rheometer with cone spindle/rotating spindle Brookfield viscometer are used.

g) Dilution studies: The smedds are diluted to 100 times in double distilled water, simulated gastric fluid (SGF) and simulated intestinal fluid (SIF). If there is increase in the dilution or the appearance is clear, then there is no drug precipitation in the formulation. The effect of ph also can be evaluated by the buffer $\mathrm{pH}$ 1.2, 6.8 and distilled water and should be observed for transparency.

h) Refractive index: The property which can evaluate the isotropic nature of the emulsion. Constant refractive index shows the thermodynamic stability of the formulation. They are measured with the refractometers and compared with water. It depends on the nature and amount of co-surfactant and the globule size of the formulation. Lower the refractive index, higher the co surfactant concentration, and lower the rigidity of micro emulsion.

i) $\%$ Transmittance: The formulation is added in water and checked spectrophotometrically. If it is near to $100 \%$ then the emulsion is clear and transparent.

j) Transmission electron microscopy (TEM): Investigates the structures and morphology of micro emulsion by dilution of SMEDDS.

k) Differential Scanning Colorimetry and NMR techniques: DSC gives information about water which is in free state and bound state. In NMR, Fourier transformed pulsed gradient spin echo method (PGSE) PGSE-NMR

l) Thermodynamic Stability Studies: This study is for stability and to evaluate the consequence of temperature change on formulations.

m) The formulation of SMEDDS are dissolved in aqueous phase and centrifuged for 15 minutes at 1500 RPM or 30 minutes at 3500 RPM. n) Freeze thawing method in which the formulation is kept at $-4{ }^{\circ} \mathrm{C}$ for freezing ( 24 hours) and at $40{ }^{\circ} \mathrm{C}$ thawing $(24$ hours) after that centrifuged for $3000 \mathrm{RPM}$ (5Min).

o) Stability Assessment: According to ICH guidelines, sample of SEMDDS are dissolved in distill water at $2-5^{\circ} \mathrm{C}$ in cooler and at room temperature.

p) \% Drug Content: The samples of SMEDDS in $100 \mathrm{ml}$ volumetric flask are added with an extracting solvent. Then it is shaking for 1 hour (Mechanical Shaker) and kept aside for 24 hours. The sample is then filtered, and absorbances are taken in UV.

q) Phase separation study: $1 \mathrm{ml}$ sample of SMEDDS are taken with $5 \mathrm{ml} 0.1 \mathrm{~N} \mathrm{HCl}$ in a glass tube. Then the buffer $\mathrm{pH}$ 6.8 and distill water are added. They are altered for 3-4 times between 2 hours [40-43].

\section{Conflict of Interest}

Authors Declared None

\section{References}

1. Mohsin K (2012) Design of lipid-based formulations for oral administration of poorly water-soluble drug fenofibrate: Effects of digestion. AAPS PharmSciTech 13(2): 637-646.

2. Jaiswal P, Aggarwal G (2013) Bioavailability enhancdement of poorly soluble drugs by SMEEDS: A Review. Journal of Drug Delivery and Therapeutics 3(1): 98-109.

3. Patel AM, Patel JB, Patel TB, Suhagia BN, Patel TR (2013) Preparation and evaluation of self microemulsifying drug delivery system for fexofenadine hydrochloride. Journal of Drug Delivery and Therapeutics $3(4): 26-32$.

4. Jakki R, Afzal Syed M, Kandadi P, Veerabrahma K (2013) Development of a self-microemulsifying drug delivery system of domperidone: In vitro and in vivo characterization. Acta Pharmaceutica 63(2): 241-251.

5. Li S, Madan P, Lin S (2017) Effect of ionization of drug on drug solubilization in SMEDDS prepared using capmul MCM and caprylic acid. Asian Journal of Pharmaceutical Sciences 12(1): 73-82.

6. Singh B, Bandopadhyay S, Kapil R, Singh R, Katare O (2009) Selfemulsifying drug delivery systems (SEDDS): formulation development, characterization, and applications. Crit Rev Ther Drug Carrier Syst 26(5): 427-521.

7. Bora D, Borude P, Bhise K (2012) Formulation and evaluation of self microemulsifying drug delivery system of low solubility drug for enhanced solubility and dissolution. Asian Journal of Biomedical and Pharmaceutical Sciences 2(15): 7-14.

8. Pouton CW Formulation of poorly water-soluble drugs for oral administration: physicochemical and physiological issues and the lipid formulation classification system. Eur J Pharm Sci 29(3-4): 78-287.

9. Tejeswari N, Chowdary HV, Hyndavi N, Jyotsna T, Gowri Y (2014) Lipid based drug delivery system for enhancing oral bioavailability-a contemporary review. Journal of Global Trends in Pharmaceutical Sciences 5(4): 2074-2082.

10. Rahman MA, Harwansh R, Mirza MA, Hussain S, Hussain (2011) A Oral lipid based drug delivery system (LBDDS): formulation, characterization and application: a review. Curr Drug Deliv 8(4): 330345 . 
11. Ljusberg-Wahren H, Seier Nielsen F, Brogård M, Troedsson E, Müllertz A (2005) Enzymatic characterization of lipid-based drug delivery systems. Int J Pharm 298(2): 328-332.

12. Djekic L, Primorac M (2008) The influence of cosurfactants and oils on the formation of pharmaceutical microemulsions based on PEG-8 caprylic/capric glycerides. Int J Pharm 352(1-2): 231-239.

13. Hasan NM, Al-aram MS, Al-wadie MS, Althobaiti FS, Al-Malki MJ (2015) Flavored self microemulsifying lipid formulations for masking the organoleptic taste of pharmaceutical actives. Journal of Applied Pharmaceutical Science 5(11): 127-134.

14. Bolko K, Zvonar A, Gašperlin M (2014) Mixed lipid phase SMEDDS as an innovative approach to enhance resveratrol solubility. Drug Dev Ind Pharm 40(1): 102-109.

15. Mandawgade SD, Sharma S, Pathak S, Patravale VB (2008) Development of SMEDDS using natural lipophile: application to beta-Artemether delivery. Int J Pharm 362(1-2): 179-183.

16. Wei JD1, Ho HO, Chen CH, Ke WT, Chen ET, et al. (2010) Characterisation of fenofibrate dissolution delivered by a self-microemulsifying drugdelivery system. J Pharm Pharmacol 62(12): 1685-1696.

17. Subudhi MB, Jain A, Jain A, Hurkat P, Shilpi S, et al. (2013) Eudragit S100 Coated Citrus Pectin Nanoparticles for Colon Targeting of 5-Fluorouracil. Materials 8(3): 832-849.

18. Borhade VB1, Nair HA, Hegde DD (2009) Development and characterization of self-microemulsifying drug delivery system of tacrolimus for intravenous administration. Drug Dev Ind Pharm 35(5): 619-630.

19. Azeem A, Rizwan M, Ahmad FJ, Iqbal Z, Khar RK, et al. (2009) Nanoemulsion components screening and selection: a technical note. AAPS PharmSciTech 10(1): 69-76.

20. Williams HD, Sassene P, Kleberg K, Calderone M, Igonin A, et al. (2014) Toward the establishment of standardized in vitro tests for lipid-based formulations, part 4: proposing a new lipid formulation performance classification system. J Pharm Sci 103(8): 2441-2455.

21. Fagir W, Hathout RM, Sammour OA, ElShafeey AH (2015) Selfmicroemulsifying systems of Finasteride with enhanced oral bioavailability: multivariate statistical evaluation, characterization, spray-drying and in vivo studies in human volunteers. Nanomedicine (Lond.) 10(22): 3373-3389.

22. Li H, Tan Y, Yang L, Gao L, Wang T, (2015) Dissolution evaluation in vitro and bioavailability in vivo of self-microemulsifying drug delivery systems for $\mathrm{pH}$-sensitive drug loratadine. J Microencapsul 32(2): 175 180

23. Sha X, Wu J, Chen Y, Fang X (2012) Self-microemulsifying drug-delivery system for improved oral bioavailability of probucol: preparation and evaluation. Int J Nanomedicine 7: 705-712.

24. Persson LC, Porter CJ, Charman WN, Bergström CA (2013) Computational prediction of drug solubility in lipid based formulation excipients. Pharm Res 30(12): 3225-3237.

25. Cui J, Yu B, Zhao Y, Zhu W, Li H, et al. (2009) Enhancement of oral absorption of curcumin by self-microemulsifying drug delivery systems. Int J Pharm 371(1-2): 148-155.

26. Grove M, Müllertz A, Pedersen GP, Nielsen JL (2007) Bioavailability of seocalcitol III. Administration of lipid-based formulations to minipigs in the fasted and fed state. Eur J Pharm Sci 31(1): 8-15.

27. Desai J, Khatri N, Chauhan S, Seth A (2012) Design, development and optimization of self-microemulsifying drug delivery system of an antiobesity drug. J Pharm Bioallied Sci 4(Suppl 1): S21-S2.
28. Jaiswal P, Aggarwal G, Harikumar SL, Singh K (2014) Development of self-microemulsifying drug delivery system and solid-selfmicroemulsifying drug delivery system of telmisartan. Int J Pharm Investig 4(4): 195-206.

29. Huang J, Gong W, Chen Z, Huang J, Chen Q, et al. (2017) Emodin selfemulsifying platform ameliorates the expression of FN, ICAM-1 and TGF- $\beta 1$ in AGEs-induced glomerular mesangial cells by promoting absorption. Eur J Pharm Sci 99: 128-136.

30. Chen ZQ, Liu Y, Zhao JH, Wang L, Feng NP (2012) Improved oral bioavailability of poorly water-soluble indirubin by a supersaturatable self-microemulsifying drug delivery system. Int J Nanomedicine, 7: $1115-1125$

31. Hyma P, Abbulu K (2013) Formulation and characterisation of selfmicroemulsifying drug delivery system of pioglitazone. Biomedicine and Preventive Nutrition 3(4): 345-350.

32. Ke ZC, Ch ZY (2012) Design and evaluation of self-microemulsifying drug delivery system (SMEDDS) of Naproxen. Lat. Am J Pharm 31(7): 1074-1078.

33. Patel RN, Tbaviskar D, Rajput AP (2013) Development and in-vivo characterization of SMEDDS (Self-microemulsifying drug delivery system) for gemfibrozil. International Journal of Pharmacy and Pharmaceutical Sciences 5(3): 793-800.

34. Ramkanth S, Kumar AJ, Gopinath C (2016) Preparation and characterization of self-microemulsifying drug delivery system of carvedilol. Int J Res Pharm Sci 7(2): 157-163.

35. Wei L, Sun P, Nie S, Pan W (2005) Preparation and evaluation of SEDDS and SMEDDS containing carvedilol. Drug Dev Ind Pharm 31(8): 785794.

36. Kim HJ, Yoon KA, Hahn M, Park ES, Chi SC (2000) Preparation and in vitro evaluation of self-microemulsifying drug delivery systems containing idebenone. Drug Dev Ind Pharm 26(5): 523-529.

37. Dixit AR, Rajput SJ, Patel SG (2010) Preparation and bioavailability assessment of SMEDDS containing valsartan. AAPS PharmSciTech 11(1): 314-321.

38. Sweta VD (2014) Formulation \& in-vitro evaluation of selfmicroemulsifying dreug delivery system of carvedilol. Int J Uni Pharm Bio Sci 3(2): 393-405.

39. Vadlamudi HC, Raju P, Venkata BRM, Thanniru J, Vandana KR (2016) Potential of Microemulsified Entacapone Drug Delivery Systems in the Management of Acute Parkinson's Disease. Journal of Acute Disease 5(4): 315-325.

40. Li C, Liu CS, Chen QZ, Wang S, Xiaong Y, et al. (2017) Characterization, Pharmacokinetics and Tissue Distribution of Chlorogenic Acid-Loaded Self-Microemulsifying Drug Delivery System. European Journal of Pharmaceutical Sciences 100: 102-108.

41. Bansode ST, Kshirsagar SJ, Madgulkar AR, Bhalekar MR, Bandivadekar MM (2015) Design and development of SMEDDS for colon-specific drug delivery. Drug Dev Ind Pharm 42(4): 611-623.

42. Rajput DS, Amit A, Vishal J, Giri TK, Tripathi DK, et al. (2012) Novel integrated approach for the strategi delivery of hydrophobic drugs by the use of self emulsifying drug delivery system. Journal of Applied Sciences 12(6): 502-517

43. Xuan XY, Wang YJ, Tian H, Pi JX, Sun SZ (2012) Study on prescription of self-microemulsifying drug delivery system of mangiferin phospholipid complex. Zhong Yao Cai 35(9): 1508-1511. 
Your next submission with Juniper Publishers will reach you the below assets

- Quality Editorial service

- Swift Peer Review

- Reprints availability

- E-prints Service

- Manuscript Podcast for convenient understanding

- Global attainment for your research

- Manuscript accessibility in different formats ( Pdf, E-pub, Full Text, Audio)

- Unceasing customer service

Track the below URL for one-step submission https://juniperpublishers.com/online-submission.php 